\title{
Estrategia de desarrollo económico en América Latina: de una visión global a una local
}

\author{
Economic development strategies in Latin \\ America: a global view to a local
}

Eugenio Trejos Benavides'

Fecha de recepción: 20 de enero del 2012

Fecha de aprobación: 19 de marzo del 2012

Trejos, E. Estrategia de desarrollo económico en América Latina: de una visión global a local. Tecnología en Marcha. Vol. 25, Nº 6. Pág 76-92 


\section{Palabras clave}

Desarrollo económico local, subdesarrollo, ajuste estructural, globalización, competitividad, América Latina.

\section{Resumen}

La incorporación de una perspectiva neoestructuralista del desarrollo permite incorporar un nuevo grupo de estrategias de desarrollo económico, denominado "desde adentro", que permite transitar de la visión global que caracteriza las estrategias de desarrollo "hacia adentro" y "hacia afuera", que han sido prescritas como la solución para los problemas estructurales causantes del subdesarrollo de los países latinoamericanos, hacia una visión local, centrada en el estímulo del mercado interno o externo, a partir de las iniciativas que surgen de las propias comunidades, de los gobiernos locales, de las instituciones nacionales con presencia en la localidad o de las entidades de economía social, que potencien un desarrollo humano equitativo y sostenible.

\section{Key words}

Local economic development, underdevelopment, structural adjustment, globalization, competitiveness, Latin America.

\begin{abstract}
The mainstreaming of development neostructuralist can incorporate a new set of economic development strategies, called "inside", which allows transit of the global vision that characterizes development strategies "inward" and "outward", which have been prescribed as the solution to the structural problems that cause underdevelopment of Latin American countries, to a local vision, focused on stimulating domestic or foreign market, from initiatives arising from the communities, local governments, of national institutions with a presence in the town or the social economy organizations, that promote equitable human development and sustainable.
\end{abstract}

\section{Hacia una clasificación renovada de las estrategias de desarrollo:"desde adentro"}

A los dos grandes grupos de estrategias que han sido prescritas como la solución para los problemas del subdesarrollo de los países latinoamericanos ("hacia adentro" $y$ "hacia afuera") puede adicionarse un nuevo grupo de estrategias de desarrollo denominado "desde adentro", cuya base de crecimiento se centra en el desarrollo del mercado, bien sea interno o externo, a partir de las iniciativas que surgen de las propias comunidades, de los gobiernos locales, de las instituciones nacionales con presencia en la localidad o de las organizaciones de economía social, para fomentar la inversión, la competitividad, la incorporación deliberada y sistemática de las innovaciones tecnológicas al proceso productivo, el estímulo del espíritu emprendedor y el apoyo a la micro, pequeña y mediana empresa nacional, que posibiliten la generación de empleo de calidad en forma sostenida y potencien un desarrollo humano equitativo y sostenible.

Al igual que se hizo para el análisis de los fundamentos básicos de las estrategias de desarrollo "hacia adentro" y "hacia afuera", y en la línea de trabajo trazada por De Franco ( 1989), se utilizará una matriz de tres sectores de actividad (agricultura, industria y servicios) y se incorporará en la orientación del mercado una nueva estrategia de desarrollo "desde adentro", lo cual amplía a nueve las posibles alternativas de estrategias de desarrollo.

Tal y como se indicó anteriormente, la separación entre los cuadrantes no significa de modo alguno que los países adopten solo un tipo de estrategia, sino que pueden impulsar una mezcla de estrategias. Sin embargo, en ciertos países es frecuente encontrar una estrategia dominante en la cual coexisten resabios de las estrategias anteriores y los incipientes elementos de las futuras estrategias. 
La piedra angular de la estrategia "desde adentro" es, desde una perspectiva neoestructuralista', la creación de las condiciones necesarias, a partir del patrimonio socio cultural e histórico (la población y sus características demográficas, sus valores y tradiciones, sus niveles educativos y de salud, sus capacidades científicas y tecnológicas, su organización institucional y empresarial, sus corrientes ideológicas, sus regímenes políticos, entre otros), del patrimonio natural (el territorio, las características de sus ecosistemas, la disponibilidad actual de sus recursos naturales renovables y no renovables, entre otras) y del patrimonio de capital fijo (la infraestructura, la capacidad productiva instalada y acumulada, entre otros), conformar una estructura productiva que permita reducir su heterogeneidad estructural, mejorar la inserción de la economía de los países latinoamericanos en los mercados internacionales, incrementar la generación de empleo decente,

I Esta corriente de pensamiento se nutre del legado positivo de un ideario propiamente latinoamericano: el estructuralismo de las décadas que precedieron a la Segunda Guerra Mundial. Así, de manera consecuente con los postulados de aquella escuela, el neoestructuralismo de nuestros días afirma, en lo fundamental, que la condición de subdesarrollo que persiste en los países latinoamericanos no se debe tanto a distorsiones inducidas por la política económica, sino que es de índole endógena y estructural. Una muestra elocuente de esta realidad subyace en tres características decisivas que la economía latinoamericana presenta en la actualidad y que ya exhibía desde décadas atrás (Rosales, 1988) en primer lugar, la vigencia de un modelo de inserción comercial que, dadas las tendencias del comercio internacional, conduce a una especialización productiva empobrecedora; en segundo lugar el predominio de un modelo productivo desarticulado, vulnerable y altamente heterogéneo y concentrador del avance tecnológico, incapaz de absorber productivamente el aumento de la fuerza de trabajo; en tercer lugar, la persistencia de una distribución del ingreso altamente concentrada y excluyente, que evidencia la incapacidad del sistema para reducir la pobreza y la desigualdad social.

Ante esta situación, el neoestructuralismo plantea, entre otras cosas, que se necesita generar un proceso dinámico de crecimiento económico en el que una liberalización que favorezca precios correctos para la asignación óptima de los factores productivos resulta insuficiente si no es complementada por una intervención activa del Estado que, a parte de sus funciones clásicas (bienes públicos, equilibrios macroeconómicos, equidad) incluya dentro de los límites de su capacidad administrativa lo siguiente: primero, la promoción o simulación de mercados ausentes (mercados de capital de largo plazo, mercado de divisas a futuro); segundo, el fortalecimiento de mercados incompletos (el tecnológico); tercero, la superación o enmienda de las distorsiones estructurales (heterogeneidad de la estructura productiva, concentración de la propiedad, segmentación del mercado de capital y del trabajo); cuarto, la eliminación o composición de la más importantes fallas del mercado derivadas de rendimientos de escala, aprendizaje (industrial o del sector externo) y externalidades (Ramos y Sunkel, |99|)
Matriz $N^{\circ} 2$ Alternativas de las estrategias de desarrollo hacia adentro y hacia afuera, y desde adentro

\begin{tabular}{|c|c|c|c|}
\hline Sectores & \multicolumn{3}{|c|}{ Orientación del mercado } \\
\hline & $\begin{array}{c}\text { "Hacia } \\
\text { adentro" }\end{array}$ & $\begin{array}{c}\text { "Hacia } \\
\text { afuera" }\end{array}$ & $\begin{array}{c}\text { "Desde } \\
\text { adentro" }\end{array}$ \\
\hline Agricultura & 1 & 2 & 7 \\
\hline Industria & 3 & 4 & 8 \\
\hline Servicios & 5 & 6 & 9 \\
\hline
\end{tabular}

mejorar la distribución del ingreso y aliviar la situación de extrema pobreza en la que viven amplios sectores de la población latinoamericana (CEPAL, 1990).

Este horizonte de largo plazo se entrelaza con una visión de corto y mediano plazo que se traduce en una serie de políticas y acciones que tienden a potenciar el capital social, cualificar el talento humano según las necesidades de la demanda empresarial local y promover el espíritu emprendedor; estimular la conformación de aglomeraciones empresariales (cluster) y la cooperación empresarial; fomentar los encadenamientos productivos de las grandes empresas, nacionales o extrajeras con las micro, pequeñas y medianas empresas nacionales (Mipymes), la incorporación constante de innovaciones institucionales o tecnológicas en los procesos productivos; elevar la competitividad de las empresas con miras al aprendizaje empresarial y al desarrollo exportador; generar un mayor empleo decente en el medio urbano y rural, de tal manera que se produzca un mejoramiento mayor en la calidad de vida de los habitantes de la región.

De este modo, la estrategia de desarrollo "desde adentro" tiende un amplio puente entre lo global y lo local. En sus planteamientos considera las cuatro grandes tendencias mundiales que condicionan actualmente los procesos de desarrollo de los países: primera, en el ámbito económico, la globalización; segunda, en el ámbito ambiental, la interdependencia a escala planetaria de los ecosistemas y de la actividad humana; tercera, en el ámbito social, las diversas conquistas sociales (educación, salud, seguridad social, entre otros) como derechos humanos fundamentales y bienes públicos globales; cuarta, en el ámbito político e institucional, la 
democracia y la participación ciudadana. Formula sus planteamientos con unas bases más próximas a los fines y principios filosóficos del desarrollo sostenible, ${ }^{2}$ y a los fundamentos del desarrollo económico local ${ }^{3}$.

2 En 1987, la Comisión Mundial sobre Medio Ambiente y Desarrollo (WCED, siglas en inglés) presidida por la Primera Ministra de Noruega, Gro Harlem Brundtland, presentó ante la Asamblea General de las Naciones Unidas (ONU) el documento Nuestro Futuro común -mejor conocido como el Informe Brundtland-, cuatro años después que la Comisión fuera creada. El documento se centra en los vínculos entre la economía y la ecología, a fin de que gobiernos y sociedades puedan actuar responsablemente con respecto a los daños ambientales y a las decisiones políticas que los producen. Se considera que es el primer documento importante de la agenda internacional del desarrollo, pues plantea el desarrollo sostenible como meta para todas las naciones del mundo: $<<$ hemos visto que se requiere un nuevo modelo de crecimiento, uno de progreso humano sostenido no solamente en unos pocos lugares para unos pocos años, sino para todo el planeta a largo plazo. De esta forma, el "desarrollo sostenible" se convierte en una meta no solamente para las naciones "en desarrollo", sino también para las naciones "industrializadas">> Además, plantea un modelo de desarrollo que lo define de la siguiente manera: $<<$ El desarrollo sostenible es aquel que satisface las necesidades de la generación presente sin comprometer la capacidad de las generaciones futuras para satisfacer sus propias necesidades" y como "un proceso de cambio en el cual la explotación de los recursos, la orientación de la evolución tecnológica y la modificación de las instituciones están acordes y acrecientan el potencial actual y futuro para satisfacer las necesidades y aspiraciones humanas $>>$. Esta definición contiene dos ideas clave: la de "necesidades", en especial las de los más pobres, a los que se les debe otorgar prioridad, y la de limitaciones impuestas por el estado de la tecnología y la organización social sobre la capacidad del medio ambiente para satisfacer las necesidades presentes $y$ futuras.

3 El desarrollo económico local recupera la dimensión territorial del desarrollo sostenible. Se basa en la identificación y aprovechamiento de los recursos y potencialidades endógenas de una comunidad, ciudad o región para mejorar las condiciones y calidad de vida de su población, mediante una acción decidida y concertada entre los diferentes agentes socioeconómicos locales, públicos y privados. La política de desarrollo local se ha sustentado hasta ahora en los siguientes ejes estratégicos (Tomás, 2008): (I) Fomento de la inversión, tanto interna como externa, y de la creación de empleo. (2) Movilización del potencial de desarrollo endógeno, como garantía de autonomía y sostenibilidad económica del proceso de crecimiento. (3) Difusión de innovaciones y el conocimiento del sistema productivo, como vehículo de competitividad y adaptación al cambio del entorno. (4) Formación, reciclaje del capital humano e inserción laboral, como vehículo de adaptación económica y estabilidad social (5) Articulación más eficiente del espacio urbano y mejora del atractivo de las ciudades para atraer a las empresas. (6) Creación de coaliciones de desarrollo entre actores privados y públicos e intereses diferentes, con el objeto de incrementar la eficacia de las políticas y la gobernabilidad de los procesos de adaptación. (7) Fomento de la internacionalización empresarial para impulsar la base exportadora, las competencias empresariales y la integración de la economía local en la economía global. (8) Desarrollo de las tecnologías de información y de las comunicaciones, y su uso por el tejido empresarial y los ciudadanos.
La experiencia muestra con claridad que tanto los fines como el significado de desarrollo sostenible necesitan adaptarse o sintonizarse con el contexto de los de lugares concretos. Esto es, en parte, porque las estructuras sociales, climáticas y ecológicas que definen la sostenibilidad varían de un lugar a otro.

Pero, además de que el desarrollo sostenible lo exige, la aproximación a lo local resulta ser, desde la perspectiva científica, una fuente de numerosas experiencias positivas, hasta tal punto que las nuevas orientaciones de la gobernabilidad para el desarrollo sostenible les otorgan un doble papel a las iniciativas regionales y locales: por una parte, el de poder convertirse en difusores de iniciativas a otras localidades y regiones, pero no por medio de las instituciones nacionales o internacionales, sino mediante procesos de difusión horizontal como los que están desarrollando las redes de científicos y las ONG ambientales o industriales; y por otra parte, que las iniciativas locales y regionales pueden funcionar como si se tratara de un laboratorio de experiencia, permitiendo preseleccionar iniciativas que pueden convertirse en políticas de la escala nacional (Clark et al. 2005, y Beishwitz, 2003, citados en Erias y Álvarez-Campana, 2007, p. 437-438).

En efecto, uno de los elementos fundamentales del desarrollo sostenible es, justamente, la concreción, la proximidad con la ciudadanía y la capacidad operativa de trasladar el concepto de desarrollo sostenible a la vida cotidiana de las comunidades locales y de los municipios, y estimular la participación ciudadana.

A continuación se analizarán los fundamentos esenciales de la estrategia de desarrollo "desde adentro".

\section{Producción desde adentro de bienes primarios}

Las preocupaciones por la oferta agrícola y el empleo que desde los años cincuenta ${ }^{4}$ han

4 El siglo $X X$ fue testigo de excepción de la denominada Revolución Verde. Entre 1960 y 1990, los países subdesarrollados experimentaron un enorme auge en la productividad agrícola. En esos decenios, en muchas regiones del mundo, especialmente en Asia y América Latina, la producción de los principales cultivos de cereales (arroz, trigo y maíz) se multiplicó, y la producción de otros cultivos aumentó grandemente. En esta revolución a la enorme cantidad de recursos que tanto los países desarrollados como los países subdesarrollados invirtieron en investigación tecnológica y desarrollo agrícola hubo grandes innovaciones en la agroquímica, 
ocupado la atención del pensamiento económico latinoamericano mantienen plena vigencia (Edmar Bacha, 198I; Lance Taylor, 1983). Obviamente, han variado los enfoques e interpretaciones a raíz de las transformaciones de la realidad del sector agropecuario y forestal acontecidas en la región en las últimas dos décadas.

Entre las variables que afectan las condiciones de la oferta y demanda de los bienes agrícolas figuran el sistema de uso y tenencia de la tierra, el desarrollo tecnológico, las condiciones del mercado internacional de bienes agrícolas y el papel desempeñado por las empresas transnacionales en la industria agroalimentaria y las políticas macroeconómicas adoptadas por los Gobiernos. Estas últimas, influyen de manera decisiva en la demanda de productos agrícolas y en los términos de intercambio, a través del tipo de cambio, el gasto público y la demanda efectiva.

Por otra parte, los cambios en los mercados internacionales -especialmente los que ocurren en las políticas agrícolas de los países ricos- influyen en el desarrollo de la agricultura de los países pobres. La política agrícola proteccionista de estos países desarrollados, se traduce en precios deprimidos de los bienes agroalimentarios en los mercados internacionales, lo que deteriora los términos de intercambio y hace más vulnerables y dependientes a los países subdesarrollados.

para producir nuevos plaguicidas y fertilizantes; y la cría intensiva y la selección genética permitieron producir variedades de alto rendimiento de cultivos y razas más productivas de ganado. Además, los gobiernos apoyaron a los productores al fomentar el uso de estas nuevas técnicas y tecnologías agrícolas. El crecimiento de la población y de la demanda, incrementaron la producción de alimentos y sus precios se mantuvieron estables.

No obstante, la revolución verde tuvo un alto costo: primero significó la pérdida de gran parte de la biodiversidad agrícola. Cuando los agricultores decidieron producir las variedades mejoradas de cultivos y de ganado, se abandonaron muchas variedades tradicionales, locales, que se extinguieron. Segundo, el uso indiscriminado de plaguicidas y otras sustancias agroquímicas produjo un serio deterioro del ambiente y puso en peligro la salud pública. Tercero, la fabricación de productos agrícolas que requieren sistemas artificiales de irrigación ejerció una enorme presión sobre los recursos hídricos. Por último, a pesar de que aumentó la productividad agrícola, sigue habiendo hambre. Para aprovechar los adelantos de la revolución verde, los agricultores necesitan tener dinero y acceso a recursos como la tierra y el agua. Los agricultores pobres que no tenían estos recursos, quedaron excluidos de la revolución verde. Muchos se hicieron todavía más pobres y no pueden comprar alimentos. Más de mil millones de personas subsisten con menos de un dólar al día (FAO, 20I I).
Esta situación se ve agravada por la creciente participación de las corporaciones transnacionales del agro negocio (Cargill, Monsanto, entre otras), que mediante sus filiales en los países subdesarrollados, especialmente en América Latina, han copado gran parte de las actividades del agro y de la producción de alimentos, modificando los patrones de consumo de alimentos y la estructura productiva de estos países 5 .

En efecto, las industrias de insumos y de procesamiento de productos agropecuarios están reestructurando y subordinando el sistema agroalimentario latinoamericano. Estas industrias no solo ha asumido el protagonismo de las relaciones entre la producción y el consumo, por medio de la producción industrial de alimentos, tanto para animales como para humanos, sino también han intensificado su esfuerzo para reducir su dependencia de ciertos insumos de origen agropecuario para la producción de alimentos, mediante el uso intensivo de la ciencia y la tecnología, y en particular, de la ingeniería genética y la biotecnología.

Este esfuerzo incluye el desmantelamiento del régimen agroalimentario tal cual se conoce en la actualidad, y su reemplazo por otro más flexible que se adapte a los imperativos de las redes de información, capital y decisiones que caracterizan las demás actividades productivas. La parte de la agricultura latinoamericana que no se adapte a esta racionalidad será excluida de las redes de poder donde se manejan las decisiones más relevantes asociadas al futuro de la agricultura comercial global (De Souza Silva, José, 1999).

Adicionalmente,losproductoresagrícolas de lospaíses latinoamericanos están perdiendo su espacio en las decisiones más relevantes relativas a la producción, así como en la interacción con los consumidores. Además, con la adhesión de estos países a la Organización Mundial del Comercio (OMC) y la suscripción de tratados de libre comercio con los países desarrollados, los países latinoamericanos se han visto forzados a introducir sistemas de protección intelectual que guarden armonía con el marco normativo de dicha organización, e incluso,

5 Desde la década de los ochenta, las corporaciones transnacionales productoras de insumos y transformadoras de productos han invertido en el desarrollo de la biotecnología moderna y en la compra de las empresas de semillas que ocupaban mercados internacionales seguros y lucrativos. 
que lo superen. Esto permite al capital industrial penetrar la agricultura en una forma sin precedentes, especialmente en la parte de la agricultura que no será reemplazada por la producción industrial de alimentos naturales fabricados. En este caso, como señala De Souza Silva (1999), la semilla constituye el vehículo biológico de los intereses económicos, corporativos y transnacionales situados fuera y no dentro de la finca ${ }^{6}$.

Un cambio importante que se produjo en el análisis del sector agrícola en la últimas dos décadas fue considerar la variable tecnológica como una variable endógena y no exógena, como ocurría en la décadas anteriores. Las empresas transnacionales han sido, en buena medida, las generadoras y difusoras de las innovaciones tecnológicas, en la que la lógica dominante es la monopolización. El conocimiento se genera en los institutos internacionales (como CIMMYT, CIAT CIP e IRRI), donde la lógica es centralizar la investigación en la sede y difundirla mediante los centros nacionales oficiales de los países. De este modo, los recursos estatales se gastan en difundir y aprender a manejar la tecnología importada y muy poco a la investigación tecnológica para resolver problemas específicos de cada país o región (Figueroa, Adolfo, 1991).

Cabe señalar que uno de los desarrollos tecnológicos controversiales en manos de las grandes empresas multinacionales de agro negocios, como se indicó anteriormente, es el que se ha dado en el campo de la biotecnología, específicamente en el área de la ingeniería genética, con la creación de lo que se conoce como "organismos modificados genéticamente" (OMG), también llamados "transgénicos". Los opositores a los alimentos

6 Mediante la ingeniería genética, las empresas transnacionales que dominan el mercado de plantas transgénicas han logrado determinar una secuencia suicida - provocada por catalizadores externos- que esteriliza la capacidad de germinar de la semilla, con el propósito de impedir que los agricultores puedan usar semillas de sus cosechas para plantar en los años subsecuentes. En un futuro no muy lejano, los aspectos críticos del proceso productivo estarán predeterminados en el código genético de la semilla. En ella estará anticipada la condición agroecológica y edafoclimática para el cultivo, los insumos por él requeridos, la forma de cosechar el producto final, entre otros

7 Ante los riesgos que entrañen los nuevos alimentos transgénicos, la FAO recomienda a sus Países Miembros que cada nueva variedad transgénica de cultivo o de animal se debe someter a prueba individualmente, con métodos científicos rigurosos, a fin de observar sus posibles beneficios y riesgos. Este proceso debe ser totalmente transparente, para que el público esté seguro de que en los transgénicos consideran que el consumo de estos alimentos puede tener efectos nocivos o que su producción puede generar daños irreparables en el medio ambiente ${ }^{7}$.

Además, señalan que de mantenerse el patrón actual de apropiación privada de los avances de la ingeniería genética, y con este tipo de cultivos, la agricultura del futuro será una agricultura científica donde prevalecerán los intereses de las grandes corporaciones transnacionales ${ }^{8}$ sobre la agricultura tradicional y el suministro mundial de alimentos, y que no beneficiará a las personas pobres que pasan hambre. Por ello es fundamental que los países subdesarrollados cuenten con centros de investigaciones biotecnológicas, en los que concurran gobierno, universidad y empresa privada, para crear variedades de plantas y animales que puedan beneficiar a los agricultores pobres y a las personas que sufren de hambre en todo el mundo, sin causar daños al medio ambiente.

Por otro lado, pese a su gran integración -aunque de manera subordinada- a la economía capitalista, la racionalidad de la economía campesina está signada por una fuerte aversión al riesgo, por lo que los procesos de difusión y aprendizaje de nuevas tecnologías en esta economía son lentos y desiguales. A ello hay que abonarle el dinamismo del mercado, las políticas públicas y la calidad de los recursos disponibles.

Otro cambio importante que se produjo en las últimas dos décadas en el análisis del sector agrícola es la creciente preocupación por la sostenibilidad de los recursos naturales, en especial la relación entre los sistemas productivos y los ecosistemas. Aun cuando existe un evidente impacto negativo de la actividad agrícola sobre el ambiente, cada día

resultados no influyeron intereses políticos ni económicos; en él deben participar las organizaciones ambientalistas, de agricultores y de la comunidad. Desde 1991, la FAO y la Organización Mundial de la Salud (OMS) ofrecen asesoramiento científico experto sobre los aspectos relacionados con la inocuidad de los alimentos, para aquellos producidos con medios biotecnológicos. La FAO y la OMS son responsables de la Comisión del Codex Alimentarius: un comité internacional dedicado a establecer normas para todos los aspectos de la inocuidad de los alimentos.

8 Dado que los principales inversionistas y creadores de cultivos y ganado transgénico son grandes empresas multinacionales, cuyo propósito fundamental es maximizar sus utilidades, la tecnología desarrollada se ha destinado a la creación de un número limitado de cultivos comerciales para los mayores productores, y no para mejorar los cultivos que ayuden a los agricultores pobres de los países subdesarrollados. 
son más las experiencias exitosas que demuestran que es posible impulsar prácticas productivas más amigables con el ambiente.

Justamente, en respuesta a la tendencia privatizadora corporativa transnacional, han emergido diversos movimientos que proclaman por el desarrollo de una agricultura sostenible, tales como agricultura orgánica agricultura ecológica, agricultura generativa, agricultura biológica y agricultura de bajos insumos, que están alcanzando algunos éxitos relevantes. Sin embargo, su alcance es limitado, debido a su dispersión y su territorialidad que los debilita frente a la sociedad en general. Construir un marco conceptual común para orientar la práctica de un paradigma alternativo para la agricultura y consolidar sus propuestas, y a la vez afirmar sus identidades es un imperativo para contrarrestar la corriente establecida por las industrias de insumos y de procesamiento de productos agropecuarios que están reestructurando y subordinando el sistema agroalimentario latinoamericano.

Adicionalmente, el acelerado proceso de urbanización de muchos países latinoamericanos ha contribuido a la conformación de una población urbana con escasa educación para reconocer la interdependencia entre el campo y la ciudad. Amplios sectores sociales urbanos difícilmente perciben la relación de algunos de sus intereses como consumidores con el desempeño de la agricultura. Por ello es una tarea impostergable ganar adeptos de la agricultura sostenible, entre los consumidores urbanos. Los costos ambientales, sociales y económicos incurridos con el modelo productivista y del paradigma dominante en la agricultura comercial pueden ser articulados y empleados como argumentos en los procesos de educación y concientización de la población urbana.

Otra transformación relevante que se produjo recientemente en el análisis del sector agrícola fue la mayor preocupación por el tema de la seguridad y la soberanía alimentaria. El consumo per cápita de alimentos en las naciones latinoamericanas se encuentra por debajo de los niveles adecuados, y casi ninguna nación ha logrado erradicar la desnutrición. Ello obedece, entre otros factores, a la limitada oferta de alimentos y a la inequitativa distribución de los ingresos.

La nueva estructura agraria que se ha formado con las transformaciones que se han dado en
América Latina en las últimas dos décadas aún está condicionada por la pérdida de su importancia relativa como sector generador de divisas y su inserción subordinada en la economía global y sus relaciones de dependencia, por la concentración de la tierra en pocas manos y la presencia del sistema de tenencia latifundio-minifundio, por el acceso limitado del medio rural -aunque también nacional- a los recursos y a la tecnología, por la mayor estacionalidad en los requerimientos de mano de obra en los calendarios agrícolas, por el débil desarrollo de las instituciones capitalistas en el sector rural, por la coexistencia de las formas de producción capitalista y la campesina tradicional, por la incertidumbre tanto en el proceso productivo como en el comercio por la naturaleza misma de la actividad agrícola como por razones institucionales, por lo exógeno de las políticas macroeconómicas y la demanda de productos agrícolas, entre otras.

En este contexto, la racionalidad económica de las unidades de producción agrícola en los países latinoamericanos puede entenderse de la siguiente manera: las empresas capitalistas buscan maximizar sus ganancias, pero tomando en cuenta el riesgo que implica la opción de ganancia que enfrenten, mientras que las unidades campesinas priorizan la minimización del riesgo, y con base en ello, consideran las opciones de ingreso que enfrentan, es decir, tienen una aversión al riesgo (Figueroa, Adolfo, 1991).

En América Latina, uno de los principales conflictos que enfrenta la política económica agraria es producir alimentos baratos y generar, al mismo tiempo, ingresos altos. Este conflicto no ha sido resuelto y es fuente generadora de conflictos sociales, ya que existe un importante grupo de consumidores urbanos y rurales en condición de pobreza o que sus ingresos reales son muy bajos y no pueden pagar precios por los productos agrícolas por encima de los que rigen en los mercados internacionales. Además, en estos países no hay una política de protección de su agricultura que le permita un rápido crecimiento y un mejoramiento de su tecnología y productividad. Con esta situación, aunada a que la división internacional del trabajo se basa cada vez menos en la dotación de recursos naturales y cada vez más en las diferencias de desarrollo tecnológico, no es de sorprender que los sectores más dinámicos de agricultura sean los que se dedican a exportar y que muchos de los 
otros sectores agrícolas se hayan constituido en un reservorio de pobreza.

Las políticas macroeconómicas deben contribuir a la creación de un ambiente propicio para el desarrollo agrario. Estas políticas no deben restringirse a liberalizar los mercados, sino que deben -dadas las condiciones de pobreza y bajos ingresos de importantes segmentos de la población urbana y rural- estimular la demanda interna mediante una política de salarios reales crecientes, toda vez que su estructura agraria es más intensiva en la producción de bienes internos?. Esta política debe ser acompañada por otra de incremento de la oferta exportable, para mantener el equilibrio externo. Para aumentar, a su vez, la oferta exportable, necesariamente debe incrementar la productividad agrícola mediante la introducción constante y deliberada de innovaciones institucionales o tecnológicas en los procesos productivos, para lo cual se requiere una fuerte inversión pública ${ }^{10}$ y privada sostenida.

En ese orden de cosas, por un lado, el Estado puede promover el desarrollo de los mercados a futuro y de seguros agrícolas, de tal manera que ofrezcan al agricultor la posibilidad de desplazar o compartir el riesgo con otros agentes privados. Por otro lado, el estímulo a los agricultores para realizar una mayor inversión vendría dado por la rentabilidad económica, y para compensar la incertidumbre a la que está sujeta la actividad agrícola donde los resultados de la producción es muy aleatoria -lo que genera inestabilidad en los precios y los ingresos agrícolas- se podría establecer una política de precios que permita que los riesgos no sean asumidos únicamente por los agricultores, sino que sean compartidos con el resto de la sociedad.

9 Los agricultores producen principalmente alimentos básicos para el mercado interno; por lo que su dependencia de la demanda interna es enorme. Por ello, una política de salarios reales crecientes es fundamental para expandir esa demanda.

I0 En los países latinoamericanos, la inversión pública en relación con el gasto público se ha reducido drásticamente. De acuerdo con la FAO (1988), la proporción del gasto público destinada a la agricultura se redujo en la región de un $8.1 \%$ en 1975 a un 6.2\% en 1980 , y a un $4.7 \%$ en 1985.

II Una política de devaluación del tipo de cambio puede producir, a nivel macroeconómico, una mayor inestabilidad, al contribuir a una inflación más elevada.
En ese sentido, se podrían implementar programas de precios de garantía y bandas de precios. De igual manera, se podría instaurar un sistema de protección selectivo y temporal mediante políticas arancelarias y cambiarias". También es tarea urgente desarrollar el sistema financiero rural mediante una política de aumento de los recursos crediticios y reforzamiento de la captación de recursos del propio medio rural, la reducción de la tasa de interés y de los costos de operación de las entidades financieras como las cooperativas, el mejoramiento de la infraestructura, especialmente las telecomunicaciones,y la generación de economías externas.

Otra manera de reducir el riesgo económico es dirigiendo la investigación e innovación tecnológica al desarrollo de nuevas variedades de cultivos de alto rendimiento y resistentes a las plagas, así como de innovaciones y servicios para la post cosecha $^{12}$. En esta misma línea, se podría establecer una política de fomento a la agroindustria, es decir, de industrializar los productos agrícolas, darles un mayor valor añadido, elevar y estabilizar los ingresos y el empleo en el campo.

En la mayoría de los países latinoamericanos, la agricultura campesina ${ }^{13}$ incorpora una proporción bastante elevada de la población rural y opera en fincas pequeñas y en tierras de baja productividad, razón por la cual su nivel de ingreso es sumamente bajo y el riesgo económico es bastante elevado. Al interior de esta agricultura, existe una enorme heterogeneidad tecnológica y la adopción de las innovaciones es relativamente baja, no solo por los costos financieros que representa su adopción, sino también porque su curva logística de aprendizaje tecnológico de este campesinado es muy larga -lo cual no significa que tenga una fuerte resistencia al cambio-, dada su baja escolaridad.

12 Generalmente, los productores enfrentan las variaciones en los precios de sus productos mediante el manejo de los inventarios. Sin embargo, dado que los productos agrícolas son perecederos, el costo de almacenaje es sumamente alto.

13 Se estima que el $25 \%$ de la población total de la región se compone de familias campesinas (Ortega, 1985). El tamaño del predio suele ser de 5 a 10 hectáreas, y su forma de producción se define por dos características fundamentales: en primer lugar, el trabajo agrícola procede principalmente de la propia familia; en segundo lugar, el tamaño del predio no le permite a la familia un nivel de ingreso por encima del de subsistencia. Esta agricultura opera donde la economía capitalista no es viable que opere.

I4 El propósito sería acortar la curva logística de aprendizaje tecnológico, reducir los costos del aprendizaje y sustituir, en parte, la educación formal del campesinado. 
Pese a ello, este tipo de agricultura tiene un enorme potencial para elevar su productividad, en virtud de que el desarrollo tecnológico de las últimas décadas ha generado innovaciones en semillas híbridas y fertilizantes que no requieren grandes extensiones de terreno. El impulso de una política de extensión agrícola puede facilitar el proceso de adopción de estas nuevas tecnologías ${ }^{14}$. Esta política de extensión agrícola debe ir acompañada de una política crediticia que permita el acceso a este campesinado que opera fundamentalmente en el mercado informal y no es objeto crédito en el mercado financiero formal, e incluso ha sido tradicionalmente excluido de los programas estatales de crédito subsidiado. ${ }^{15}$

Por otra parte, dada la fuerte concentración de la propiedad de la tierra en pocas manos, es necesario una verdadero programa de reforma agraria que, bajo criterios de eficiencia y equidad, beneficie a grandes segmentos del campesinado sin tierra o con muy poca tierra, con un adecuado acceso a las fuentes de crédito y tecnológica apropiada, que rompa con el sistema latifundio-minifundio que se ha transformado en la estructura capitalista-campesino.

En la mayoría de los casos, el latifundio ha derivado en empresas capitalistas, y el minifundio en la unidad familiar campesina, la cual se vincula con la empresa agrícola capitalista y con el resto de la economía fundamentalmente mediante relaciones de mercado (Figueroa, Adolfo, 1991). De este modo, los programas de reforma agraria constituyen una valiosa herramienta para promover el desarrollo rural y requieren de una enorme voluntad política para ejecutarlos, la participación activa del campesinado favorecido para buscar nuevas formas de organización y de producción más eficientes, que contribuyan a elevar su productividad y competitividad.

Por otra parte, para hacerle frente a las condiciones internacionales desfavorables para los países

15 La División Agrícola Conjunta de la CEPAL y la FAO han estimado en once países de la región latinoamericana que el crédito subsidiado estatal tiene una cobertura inferior al 25\% de las unidades agrícolas, apoyando casi exclusivamente a las medianas y grandes unidades (CEPAL, Notas sobre la economía y el desarrollo, número 479, julio de 1989)

16 El establecimiento de un arancel a la importación de bienes agrícolas subvencionados haría que los beneficios de los precios internacionales bajos se distribuyeran entre productores y consumidores, y no solo entre consumidores; así, los fondos recaudados se podrían orientar a programas de desarrollo agrario. subdesarrollados, dadas las políticas agrícolas proteccionistas de los países desarrollados, se podrían adoptar políticas restrictivas a la importación de los productos agrícolas subvencionados ${ }^{16}$. En todo caso, la mejor manera de enfrentar estas condiciones internacionales adversas es el establecimiento de políticas efectivas de innovación tecnológica, competitividad y diversificación de la producción y de la oferta exportable agrícola.

Los países latinoamericanos enfrentan tres grandes desafíos: primero, alcanzar un desarrollo competitivo y sostenible de la agricultura, compatible con la conservación y uso adecuado de los recursos naturales; segundo, aprovechar las oportunidades de una mayor apertura del comercio agropecuario; tercero, generar actividades que contribuyan a generar fuentes de trabajo decente ${ }^{17}$ que reduzcan la desocupación y la pobreza rural. Ello exige la adopción de enfoques integrales de la ruralidad y la fijación y puesta en marcha de políticas que encaren los problemas de la competitividad, el empleo y la pobreza de un modo integrado, que dinamicen la inversión en las zonas rurales y cuenten con participación tripartita (Gobierno, empresarios y trabajadores) y otros actores sociales.

Un desarrollo agrario dinámico, competitivo y sostenible de la agricultura pasa por considerar enfoques de agronegocios que superen la visión de la agricultura como un proceso meramente extractivo de la producción primario y reconocer los sistemas de cadena de valor. Los agronegocios tienen diversas dimensiones de los grandes productores y con vinculaciones transnacionales, hasta el pequeño relacionado con la producción agropecuaria de reducida escala y sus encadenamientos a nivel local o regional ${ }^{18}$. El desarrollo de la agricultura compatible con la conservación y el uso adecuado de los

17 Según la Organización Internacional del Trabajo (OIT), el trabajo decente es aquella ocupación productiva que es justamente remunerada y se ejerce en condiciones de libertad, equidad, seguridad y con respeto a la dignidad humana. Ello exige la promoción, adopción y puesta en marcha de políticas laborales que enfoquen los problemas del empleo, la desocupación y la pobreza de un modo integrado, y que cuenten con participación tripartita (Gobierno, empresarios y trabajadores) y otros actores sociales.

18 Las características de los productores agrícolas en la región latinoamericana son muy heterogéneas, pues van desde los que practican la agricultura de subsistencia hasta aquellos que practican un agricultura para fines comerciales, pasando por los que practican una agricultura excedentaria. Esto se traduce en la producción de una serie de bienes agrícolas con un bajo valor agregado y en un desempeño agrícola modesto comparado con el PIB total. 
recursos naturales plantea como opciones no solo la producción limpia, sino también, entre otras cosas, la posibilidad de otros usos para los productos de la agricultura ampliada, entre los cuales se destacan la utilización de la agricultura como fuente de energía sustitutiva de los combustibles fósiles, como el petróleo, así como el desarrollo de los servicios ambientales (IICA, 2005).

Por su parte, el aprovechamiento de las oportunidades que brindan mercados más amplios producto de una mayor apertura comercial agropecuaria exige ser más competitivos, y para ello es fundamental la incorporación constante y deliberada de innovaciones institucionales o tecnológicas en los procesos productivos y el aprovechamiento de las bioagrotecnologías, para lo cual se requiere incrementar la inversión pública y privada de manera sostenida en las zonas rurales.

La reducción del desempleo y la pobreza rural necesita no solo de una agricultura competitiva e incluyente, sino también del desarrollo de las sinergias entre la producción agropecuaria y las actividades no agropecuarias en los territorios rurales, para ampliar las oportunidades de un empleo decente y mejorar los ingresos y la calidad de vida de las poblaciones rurales.

El aumento de la inversión pública y privada de manera sostenida en las zonas rurales es un prerrequisito para afrontar los desafíos anteriores. Tradicionalmente, la inversión para producir bienes públicos en las zonas rurales era una función que le correspondía solo al sector público, mientras que el sector privado únicamente invertía en la explotación comercial de recursos naturales. En la actualidad, el sector privado crecientemente adquiere conciencia de su responsabilidad social y se necesita que no solo invierta en actividades que produzcan retornos desde el punto de vista privado, sino también que deriven en retornos sociales (Morales, Briones y Ramírez, 20I I).

Finalmente, el Estado debe asumir su papel de promotor del desarrollo agrícola mediante los distintos instrumentos de política económica. Debe no solo resolver las fallas del mercado en cuanto a las distorsiones en el sistema de precios o entre los costos privados y sociales cuando del manejo de los recursos naturales y el medio ambiente se trata, sino también las enormes desigualdades de ingresos que resultan de la alta concentración de la propiedad, la sobrepoblación relativa a sus recursos y la dualidad económica.

La acción estatal debe contribuir a superar los obstáculos que impiden que la agricultura tenga un mayor dinamismo y expansión; que genere oportunidades de educación y empleo para la población rural que vive en condición de pobreza $^{19}$, que no se discrimine ni excluya a la pequeña agricultura, que los mercados ausentes 0 incompletos (financiero, tecnológico, de seguros, a futuro, entre otros) del medio rural se desarrollen, y que se organice y garantice la eficiencia institucional en la generación y difusión de las innovaciones tecnológicas ${ }^{20}$, para elevar la productividad y competitividad del sector agrícola, en particular de la agricultura campesina.

El desarrollo del sector agrícola latinoamericano requiere una adecuada combinación de políticas de mercado y de participación del Estado. El mercado, por sí solo, no garantiza el desarrollo del sector agrícola; los precios son una condición necesaria pero no suficiente para asumir con éxito esta tarea. El Estado, por sí solo, tampoco lo garantiza; el nivel de eficiencia actual del aparato estatal es relativamente bajo para enfrentar los severos problemas agrarios y promover las transformaciones estructurales que el sector agrícola exige y reclama.

\section{Producción desde dentro de bienes industriales}

19 No obstante, la FAO (20 I I) advierte que aun cuando se logre dar más oportunidades de empleo y educación en las comunidades rurales, las personas que sufren de hambre desde el nacimiento no podrán aprovecharlas, dado que el hambre y la malnutrición a que han estado sometidas las personas pobres disminuyen la salud. Los hijos de madres subnutridas a menudo son pequeños y débiles. Como el hambre afecta el sistema inmunológico, los niños subnutridos a menudo contraen graves infecciones o enfermedades como la malaria, la pulmonía, diarrea o sarampión. Como no obtienen suficientes vitaminas y minerales de su alimentación, el desarrollo físico y mental de los niños puede retrasarse y pueden tener dificultades para concentrarse y estudiar cuando están en edad de ir a la escuela.

20 El desarrollo tecnológico del sector agrícola latinoamericano es una muestra elocuente de que el mercado, por sí solo, no garantiza la generación y difusión de las nuevas tecnologías. Si bien es cierto, los precios son una condición necesaria pero no suficiente para asumir con éxito esta tarea. 
La estrategia de industrialización mediante sustitución de importaciones en América Latina permitió un crecimiento económico sin precedentes y creó una importante plataforma industrial, mediante una fuerte estructura de incentivos a la producción para el mercado interno, tales como protección arancelaria, subsidios, tipo de cambio fijo, crédito blando, entre otros. Esta estructura de incentivos -indiscriminados y prolongados- creó un "sesgo anti-exportador" que imposibilitó la expansión de las exportaciones y la generación de divisas, y desaprovechó el aliciente a la eficiencia que representa incursionar y competir en los mercados internacionales. Peor aún el caso de los países con mercado interno de escaso tamaño, se sacrificaron importantes economías de escala y la nueva tecnología que viene aparejada. Además, no se logró conformar una clase empresarial modernizadora, dinámica e innovadora, obligando al Estado cumplir una función como empresario.

La superación del abultado endeudamiento externo, el estancamiento y la inequidad exigen el diseño y aplicación de una nueva estrategia de industrialización que privilegie el incremento de productividad y competitividad en el difícil tránsito de los países latinoamericanos hacia su incorporación en los procesos mundiales de modernización y transformación productiva. Ello sugiere un mejor aprovechamiento de las señales que envía el mercado, de la iniciativa empresarial y de la competencia internacional, así como una participación activa del Estado en la creación de un marco institucional que estimule la creatividad y el dinamismo de los agentes productivos (empresarios y trabajadores) y la capacidad de concertación y coordinación entre ellos.

Este marco institucional supone, además, políticas para superar la inequidad, garantizar la estabilidad macroeconómica y proporcionar bienes públicos indispensables en la gestión productiva (infraestructura material, financiera, de servicio, de aprendizaje y desarrollo tecnológico). Se trata, en definitiva, de opciones que aprovechen al máximo la información que ofrecen los mercados internos y externos y las tendencias tecnológicas, institucionales y organizacionales (Muñoz, 1991).

La estrategia de industrialización "desde adentro" es un esfuerzo interno por configurar la estructura productiva que sea funcional a las características y potencialidades específicas nacionales (Fajnzylber, 1983). En ese sentido, en una primera etapa se busca establecer un núcleo endógeno básico de industrias consideradas fundamentales para el proceso de industrialización, acumulación, generación y difusión de las innovaciones tecnológicas e incremento de la productividad. Este es un impulso creador inicial de la industria, a partir de la utilización de la capacidad instalada y de recursos naturales hasta entonces desaprovechados, y de la articulación del territorio y del mercado nacional.

En una segunda etapa, se refuerza la creatividad interna mediante una mayor participación e interrelación entre diversos agentes y motivaciones: grandes empresas industriales vinculadas con medianas y pequeñas empresas, infraestructura científica y tecnológica (institutos de ciencias básicas y de tecnologías), ministerios y organismos que definan políticas y normas, instituciones de educación y capacitación en todos sus niveles, entre otros. La consolidación como práctica nacional, de la comunicación e interacción de estos actores, instancias y niveles de decisión, posibilita la conformación de un núcleo endógeno de dinamización tecnológica que, a su vez, estará en condiciones de generar sistemas articulados capaces de alcanzar niveles de excelencia internacional en todos los eslabones que forman la cadena de especialización productiva.

En el nuevo marco estratégico, se acepta que la reestructuración productiva y un buen desempeño exportador son necesarios y deseables ${ }^{21}$, y se dejan abiertas las opciones para orientar "desde adentro" la industrialización hacia determinados mercados internos y externos, prioritarios en las estrategias de desarrollo de largo plazo, en las que los países subdesarrollados posean o puedan adquirir niveles de productividad y competitividad relativa que les garanticen una mayor y mejor inserción en la economía mundial. En el caso de los países con

21 De hecho, tales desafíos deberían haberse abordado en la década de los setenta. Pero, dadas las actuales condiciones internas y el contexto internacional, ello requeriría un titánico esfuerzo y considerables sacrificios. Así lo señala la evidencia teórica y empírica sobre el deterioro de los términos de intercambio. En efecto, existe cierta evidencia de que dicha tendencia se ha ampliado desde las características de los productos exportados hacia las características del país exportador, abarcando también, de este modo, las exportaciones manufactureras. Este hecho obliga a insistir en la reflexión de los modos específicos de inserción internacional, los patrones de especialización productiva $y$, en consecuencia, sobre el papel de la política industrial y comercial para promover niveles de competitividad aceptables en las ramas dinámicas del comercio internacional (Ocampo, Antonio, |99|). 
economías pequeñas, estos necesariamente deben mantener mayores grados de apertura comercial que las economías de mayor tamaño, para ampliar mercados en una serie de actividades en las que solo son competitivas si se establecen a nivel mundial-como es el caso de la industria automotriz o electrónica de punta-,y aprovechar economías de escala que vienen acompañadas de tecnologías más modernas.

Para aprovechar la plataforma industrial que dejó el proceso de sustitución de importaciones y reactivar los recursos disponibles, se plantea una intervención selectiva y temporal que busque establecer ventajas comparativas dinámicas en los mercados internacionales, dado que la exportación es la próxima etapa natural de dicho proceso que, en la actualidad, consiste fundamentalmente de insumos y bienes de capital.

El incremento de la productividad y la competitividad debe ocupar un lugar de primer orden en las nuevas políticas industriales -sin perjuicio de la inversión y de la capacidad productiva-, así como de la estabilidad macroeconómica y financiera, que son indispensables para estimular la inversión privada a largo plazo. Los aranceles deben disminuirse y racionalizarse para facilitar la exportación y la sustitución de importaciones competitiva. De esta forma, en lugar de aranceles, lo importante será el subsidio a la exportación para las empresas innovadoras que introduzcan nuevos productos y abran nuevos mercados.

De igual manera, la producción de las empresas multinacionales acantonadas en la región latinoamericana ha de ser volcada hacia afuera, aprovechando su extensa red de comercio internacional, negociando compromisos de desempeño exportador, a cambio de permitir la

22 En América Latina, son cada vez más los países que realizan esfuerzos por desarrollar programas tendientes a enlazar las empresas nacionales con firmas manufactureras transnacionales. A modo de ejemplo, en Costa Rica con el propósito de aumentar el valor agregado nacional en la producción de las empresas multinacionales de alta tecnología y como consecuencia mejorar la competitividad de las pequeñas y medianas empresas nacionales, se estableció, a finales de 1999, el "Proyecto de Desarrollo de Proveedores para Empresas Multinacionales de Alta Tecnología". Como resultado de esa iniciativa, la compañía ElectroPlast, que es una empresa de capital costarricense especializada en la producción de piezas plásticas por medio de inyección de resinas, produce piezas para equipos de anestesia de Baxter, que es una multinacional fabricante de equipo médico. adquisición de insumos a precios internacionales vigentes. También han de fomentarse los encadenamientos productivos de estas empresas transnacionales con las micro, pequeñas y medianas empresas nacionales industriales y de servicios que cumplan con las características y especificaciones productivas, técnicas y de calidad que las firmas foráneas requieren, de tal manera que se aumente el valor agregado de la industria nacional y la competitividad global del país 22 .

De este modo, la reinserción dinámica e inteligente en la economía mundial con productos de mayor valor agregado y mayor contenido tecnológico, con la participación de las pequeñas y medianas empresas, adquiere especial relevancia y plantea una serie de desafíos de la política pública. El Estado debe desempeñar activo en esta estrategia ${ }^{23}$, concertando con los grandes grupos económicos y los demás agentes económicos y sociales ${ }^{24}$; interviniendo discrecionalmente en la asignación de recursos pero dejando más espacios a los mercados; estimulando la productividad y competitividad internacional a la vez que la equidad social y regional; manteniendo un compromiso con la estabilidad macroeconómica y financiera para crear un clima propicio a la inversión privada de largo aliento, pero apoyando decididamente la innovación tecnológica, y al sector Mipyme, con subsidios, protección o inversión pública directa con miras al aprendizaje empresarial y al desarrollo exportador.

En esa dirección, debe constituirse una institucionalidad que fortalezca y desarrolle una clase empresarial innovadora y motivada por el incremento de la productividad y competitividad internacional, pero con un sentido de responsabilidad social. Este enfoque de modernización industrial,

23 Las experiencias más exitosas de los países europeos y asiáticos, durante el periodo de postguerra y de reconstrucción de sus economías, muestran que todos ellos aplicaron políticas industriales que requirieron en intensidad variable, diversas formas de intervención estatal para incrementar la productividad y competitividad internacional.

24 En Europa, las políticas de industrialización fueron apoyadas por una institucionalidad para las concertaciones sociales, lo cual contribuyó a que los empresarios, trabajadores y otros sectores sociales negociaran sus aspiraciones e intereses y establecieran patrones distributivos políticamente aceptables. Por su parte, en los países asiáticos, principalmente los que fueron ocupados al término de la Segunda Guerra Mundial, se impulsaron reformas a los sistemas de propiedad, las cuales posibilitaron emprender procesos de modernización industrial con una equidad distributiva que evitó situaciones de conflicto. 
podría catalogarse como schumpeteriano, con una fuerte adaptación y orientación al comercio exterior, por cuanto se centra en el desarrollo de una clase empresarial que sabe aprovechar un ambiente institucional y económico favorable para el desarrollo de su actividad productiva.

Este ambiente se caracteriza por un sistema social muy articulado en torno a la familia, a las organizaciones de base y a los municipios, con un alto grado de descentralización en la movilización de los recursos, en la capacitación técnica, el uso de mano de obra calificada y que dispone de una adecuada infraestructura (transporte, carreteras, muelles, aeropuertos, comunicaciones, entre otros) y servicios públicos eficientes.

\section{Prestación de servicios desde dentro}

En la actualidad, una marcada tendencia de las economías de los países subdesarrolladas es transitar de la agricultura a la industria, y finalmente, hacia una economía basada en la prestación de servicios. El proceso de terciarización es un elemento fundamental en el crecimiento económico de estos países, dado el carácter intangible de los servicios que se asocia, cada vez más, a mayores tasas de incorporación de capital y tecnología, a una alto empleo de mano de obra y a un su papel dinamizador de la productividad total de los factores productivos.

La economía global va acompañada de un comercio global que deviene de las nuevas oportunidades

25 La globalización puede entenderse como un proceso histórico dinámico a gran escala de índole económica, pero con profundos impactos políticos, sociales, culturales y ambientales, que conlleva una creciente interdependencia entre los diversos países del mundo. Es el principal componente en el funcionamiento presente y futuro de la economía mundial, que permea las distintas economías y al conjunto de las relaciones económicas mundiales en todos sus niveles. Marca el tránsito de un sistema de economía nacional a un sistema de economía mundial, en el que los Estados nacionales pierden importancia, al igual que determinantes de economía nacionales. Consiste, entre otras cosas, en la integración y desregulación acelerada de los mercados y la conformación de grandes bloques económicos, la vertiginosa generación, difusión y uso intensivo de nuevas y sofisticadas tecnologías, la segmentación de procesos productivos y la progresiva disolución de los linderos que separan a los bienes de los servicios, la modificación en las formas de gestión y control de empresas y la creación de condiciones internas y externas para que los capitales nacionales e individuales, cada vez más centralizados y concentrados, puedan movilizarse con fluidez en los mercados locales y mundiales. abiertas por el vertiginoso crecimiento de intercambios de bienes, servicios y conocimiento, acuerdos internacionales, inversión extranjera directa, entre otras. En este entorno mundializado, las empresas buscan proveedores, clientes y modos de organización y estructuración de la producción en cualquier lugar del planeta. Además, las tecnologías de la comunicación y la información representan un ahorro considerable de tiempo y de dinero para muchos agentes económicos.

Los servicios se encuentran en el centro de los procesos actuales de globalización ${ }^{25}$, especialmente los servicios a empresas o servicios intermedios a la producción ${ }^{26}$, es decir, los que influencian la competitividad de cualquier empresa, independientemente del sector al que pertenezca, al ofrecerles alternativas para reducir costes o ganar calidad, e incluso acompañando a sus clientes en su aventura internacional. Estos servicios también contribuyen a la globalización de las economías y a afrontar los desafíos competitivos, pero, a su vez, resultan afectados por esa globalización, obligándose a participar de una dinámica que rompe la tradicional segmentación de mercados y a responder a los retos de la internacionalización ${ }^{27}$. Los servicios a empresas se revelan de manera creciente como factores fundamentales para la competencia dentro del entorno global (Rubalcaba, 200 I).

El sector servicios está contribuyendo activamente a los procesos de cambio de los países subdesarrollados, los cuales se están adaptando a los nuevos desafíos globales que los obliga a buscar nuevas estrategias y ventajas competitivas, como la

26 Estos servicios son aquellos que se incorporan como inputs en un proceso productivo para contribuir a generar otros bienes o servicios, o para mejorar el funcionamiento de las empresas en general. Se trata de actividades que se incorporan a las distintas áreas que configuran la organización funcional interna de una empresa, pudiendo agruparse bajo una doble clasificación: servicios reales y servicios financieros. Los servicios reales inciden en la modificación del ciclo productivo y permiten el ajuste estratégico de la empresa; son instrumentos que posibilitan una diferenciación del producto, una modificación de los procesos o un cambio en la extensión de los mercados. Estos servicios incluyen, por un lado, los llamados servicios superiores que precisan un alto nivel de especialización técnica (ingeniería, control de la calidad, diseño, gestión de redes de comunicación, entre otros), y por otro, los servicios tradicionales (contabilidad, gestión de recursos humanos, asesoría legal y fiscal, transporte, entre otros). Para una clasificación más detallada puede consultarse Cuadrado, Jr. y Del Río C. (1989)

27 La internacionalización constituye la primera fase de la integración económica y consiste en la vinculación entre los países; esta se produce, inicialmente, a través del comercio internacional y de la movilidad de factores de producción. 
internacionalización de los servicios y, en especial, los dirigidos a empresas. Hasta hace escaso tiempo, con excepción del turismo y del transporte, el sector terciario tenía una escasa participación en el comercio internacional de estos países.

Actualmente, del conjunto de flujos que representa la internacionalización de servicios, el comercio internacional aparece como una realidad decisiva; prueba de ello lo constituye el reciente proceso del llamado offshoring de servicios, es decir, la externalización y contratación internacional de estos. La deslocalización de los servicios, al igual que ha sucedido desde la década de los setenta con las empresas manufactureras, representa una fuente de empleos potenciales para estos países ${ }^{28}$.

En este contexto destaca el papel de los servicios a empresas y servicios avanzados como ejes de las nuevas posiciones competitivas. Hablar de offshoring de servicios es hablar de servicios intensivos en conocimiento, vinculados a las tecnologías de la información y la comunicación, como de operativos y back offices. Por ello, entre los principales retos para los países latinoamericanos se sitúan algunos servicios vinculados al desarrollo de las tecnologías de la información y las comunicaciones, y la sociedad del conocimiento, así como en servicios financieros, comunicaciones y seguros -que no hace mucho eran resorte solo del Estado- y el desarrollo de servicios asociados a la actividad de exportación ${ }^{29}$.

Un aspecto prioritario para enfrentar el desafío que representa competir en el mercado internacional de servicios descansa en la identificación de los sectores y empresas de servicios en los que se dispone de ventajas comparativas y analizar la evolución del

28 Caso contrario sucede en Estados Unidos y Europa, donde las pérdidas de empleos potenciales debidos al offshoring internacional se cifran en cientos de miles. Hoy la mirada del mundo se centra en economías emergentes como China e India, que presentan mayores ventajas competitivas en el fenómeno del offshoring de servicios.

29 Caso contrario sucede en Estados Unidos y Europa, donde las pérdidas de empleos potenciales debidos al offshoring internacional se cifran en cientos de miles. Hoy la mirada del mundo se centra en economías emergentes como China e India, que presentan mayores ventajas competitivas en el fenómeno del offshoring de servicios.

30 Ello haciendo la salvedad de que resulta sumamente complejo obtener los índices que podrían mostrar la capacidad competitiva de cada tipo de servicio, especialmente cuando se necesitan series largas y homogéneas de diferentes países, de ahí que los resultados que se suelen presentar están sometidos a los límites de las estadísticas que los respaldan. comercio internacional ${ }^{30}$, a efectos de administrar e integrar de manera apropiada aquellos elementos que son cruciales para fortalecer la competitividad de las empresas.

Particular atención debe prestarse al financiamiento y la asistencia técnica directa e individual a las pequeñas y medianas empresas, particularmente aquellas orientadas a la exportación. Si se crean aglomeraciones de pequeñas y medianas empresas (clusters), se podría sacar mayor provecho de los recursos técnicos y financieros que las instituciones de muy diversa naturaleza destinan al apoyo de dichas empresas. Al consolidar o complementar sus capacidades de oferta, estas agrupaciones obtienen mejores resultados que los que suelen obtener cuando actúan por separado. Al actuar en forma conjunta, las pequeñas y medianas empresas están en condiciones de optar entre varios tipos de esquemas de agrupación, a saber:empresas conjuntas (jointventures), consorcios, empresas mercantiles (trading companies), empresas de comercialización de exportaciones y grupos de interés económico ${ }^{31}$ (Rubalcaba, Gago y Maroto, 2005).

Por otra parte, a diferencia de los bienes, cuya globalización establece un conflicto entre lo local y lo global, los servicios se benefician de una complementariedad que tiende a superar en determinados casos los conflictos. Hay servicios que existen precisamente por la diversidad económica, social, geográfica o cultural. Así como el turismo precisa la existencia de diferentes destinos, los servicios lingüísticos requieren de la diversidad de lenguas y las ferias y exposiciones de la diversidad de empresas, productos e innovaciones. De ahí que los servicios faciliten la integración real de los mercados y de las economías.

Los servicios son grandes promotores de la llamada glocalisation, es decir, una globalización hecha a la medida de las necesidades locales: el propósito de la globalización es una mejor "localización", una mejor adaptación a los parámetros normativos, económicos, sociales y culturales de la región en la

31 Los países desarrollados han recurrido a algunas de estas opciones para expandir sus exportaciones de muchas pequeñas y medianas empresas; por ello, los países subdesarrollados deben revisarlas cuidadosamente $y$, en la medida de lo posible, adaptarlas a las características específicas de sus ambientes socioeconómicos y culturales, para reducir riesgos y aumentar las posibilidades de obtener el éxito de sus empresas. 
que se quiere operar. Se trata de hacer las cosas tanto a mayor escala como a menor escala. En ese sentido, los servicios a empresas contribuyen respondiendo a esta necesidad de convertir lo global en local. La diferenciación y competitividad de los servicios a empresas responde precisamente a la capacidad de distinguir aquellos elementos que combinan de modo óptimo las necesidades y los recursos que provienen tanto de lo global, como de lo local (Rubalcaba, Gago y Maroto, 2005).

En ese orden de cosas, es preciso realizar mayores esfuerzos en términos de innovación productiva en los países subdesarrollados, a efectos avanzar en la frontera tecnológica y de gestión de micro, pequeñas y medianas empresas. Sin una política específica de atención a las necesidades territoriales de los distintos sistemas productivos locales no será posible atender adecuadamente a los requerimientos de modernización empresarial de estos.

Las políticas de carácter genérico dictadas desde el nivel central del Estado resultan insuficientes y deben ser discutidas y precisadas por los responsables locales, municipales o regionales, ya que una aproximación territorial permite una identificación más precisa de la demanda de servicios de desarrollo empresarial en cada uno de los sistemas productivos locales, tanto en lo relativo a la introducción de innovaciones tecnológicas y de gestión necesarias, como en lo que se refiere a la cualificación de los recursos humanos según las necesidades de dicha demanda empresarial local (Alburquerque, 1999).

Además, los gobiernos locales y regionales poseen ventajas importantes con respecto a los gobiernos centrales, debido no solo a su mayor capacidad de representación y legitimidad ante sus electorados, que les permite ser agentes institucionales de integración social y cultural de comunidades territoriales, sino también por su mayor flexibilidad, adaptabilidad y capacidad de maniobra ante contextos cambiantes (Borja y Castells, 1997).

De ahí que el fortalecimiento de las instituciones de gestión y representación a nivel local o regional puede facilitar la construcción de redes de colaboración con los diferentes actores sociales y de cooperación entre los distintos niveles de la administración pública, promover la democracia participativa, la descentralización administrativa, la integración social y cultural, y la innovación productiva y el desarrollo empresarial.
Además, pese a la marcada tendencia a la globalización de determinadas actividades y sectores económicos dinámicos en el sistema internacional, la inmensa mayoría de la producción a nivel mundial continúa realizándose en el ámbito local, regional o nacional, y allí la importancia de las micro, pequeñas y medianas empresas es fundamental en las diversas actividades y sectores productivos, así como en la creación de empleo de calidad.

Las Mipymes juegan un papel fundamental para en la creación de empleo e ingresos para amplios sectores de la población, así como para una difusión territorial más equilibrada del avance tecnológico y el crecimiento económico. De ahí la necesidad de introducir desde la instancia territorial un enfoque de desarrollo productivo y empresarial, a la vez que se fortalecen institucionalmente los poderes locales. El fortalecimiento institucional de los gobiernos locales y el fomento de la descentralización y de la participación de la ciudadanía constituyen una condición fundamental para propiciar la concertación de actores públicos y privados territoriales, y abordar los nuevos retos de la gestión local para el desarrollo.

Las empresas no actúan en el vacío, sino en conjuntos interrelacionados de eslabonamientos de unas con otras, bien sea como abastecedoras o como clientes en las sucesivas fases de la transformación productiva. El diseño de políticas y líneas de actuaciones eficaces para mejorar los encadenamientos productivos y facilitar la modernización empresarial precisa conocer los eslabonamientos "hacia atrás" y "hacia adelante" procedentes de diversos sectores a lo largo de la "cadena de valor", los agrupamientos económicos territoriales en los que estas empresas se encuentran en la realidad, y si dichas actividades incorporan o no los componentes avanzados de información o conocimiento tecnológico y de gestión.

Una estrategia"desde adentro" orientada al desarrollo de la especialización y la complementaridad de las Mipymes dentro de acuerdos y conglomerados territoriales o clusters puede resultar decisiva para el éxito de estas empresas. Se trata de establecer grupos de firmas territoriales o clusters de una diversidad de Mipymes individualmente especializadas que trabajen en un marco de complementariedad, y de cooperación interempresarial, de forma tal que sea el grupo de empresas el sujeto colectivo quien protagoniza la pugna competitiva. 
Estas Mipymes enfrentan dos desafíos: primero, adaptarseala complejidad,dinamismoy competitividad e internacionalización de las actividades económicas que caracterizan la denominada "Sociedad de la Información y del Conocimiento"; segundo, introducir innovaciones organizativas y tecnológicas para mejorar su competitividad en un mercado cada día más excluyente. Para hacer frente a estos desafíos, las Mipymes disponen de un ventaja que se deriva de su propia naturaleza y tamaño: la ausencia de burocracia, que le brinda la flexibilidad necesaria para anticiparse o adaptarse a los cambios del entorno, y para introducir mecanismos de gestión que pongan en marcha nuevos recursos y capacidades de carácter tecnológico.

Asimismo, la calidad del entorno urbano, ambiental y territorial en que el que se encuentran inmersas las empresas condiciona enormemente su productividad y competitividad, lo cual hace necesario reforzar las actuaciones para mejorar la calidad de la infraestructura, de los servicios básicos y de los sistemas de comunicaciones para el tránsito de personas, información y mercancías en cada ciudad o ámbito local.

Los niveles óptimos de eficiencia productiva y gestión empresarial apuntan al adecuado diseño de políticas públicas y privadas en torno a dos aspectos clave del desarrollo económico: primero, la introducción de las innovaciones tecnológicas, gerenciales y sociales en los procesos de la producción y comercialización de mercancías; segundo, la cualificación de los recursos humanos, íntimamente vinculada a las demandas planteadas por este proceso de transformación socio-productiva. Especial relevancia adquiere en este contexto el estímulo del espíritu emprendedor: promover la independencia económica, favoreciendo el estímulo del talento y la creatividad.

La estabilización macroeconómica alcanzada en los países latinoamericanos con las reformas estructurales que han mejorado el funcionamiento de los mercados

32 Entre los aspectos del nivel microeconómico que deben atenderse figuran la mejora de la capacidad de gestión empresarial y tecnológica, la introducción de innovaciones productivas y de comercialización, la mejora en la cooperación interempresarial con proveedores y clientes, la calidad de las relaciones laborales y el involucramiento de trabajadores; la adecuación de la oferta de capacitación de recursos humanos a los requerimientos de la base productiva y el tejido empresarial existentes; la vinculación de las empresas con las entidades oferentes de servicios de desarrollo empresarial, entre otras. ha creado un contexto favorable para la aplicación de políticas tanto a nivel microeconómico ${ }^{32}$ para asegurar la innovación tecnológica e incidir en las formas de producción y gestión de las empresas, así como de las organizaciones en general, públicas o privadas; como a nivel mesoeconómico, para vincular la oferta de capacitación y desarrollo del talento humano a la demanda de los sectores productivos y empresariales existentes en los distintos ámbitos territoriales o locales, y para lograr un contexto institucional favorable, la disminución de los costes de transacción y un entorno de servicios empresariales, urbano, ambiental y territorial de calidad.

\section{Bibliografía}

Arroyo, G. \& Waissbluth, M. ( 1988) Desarrollo biotecnológico en la producción agroalimentaria de México: orientaciones de política. CEPAL, México, Publicación de Naciones Unidas.

Alburquerque, Francisco (1999) Servicios empresariales y desarrollo económico local: una reseña temática. Banco Interamericano de Desarrollo, Washington D.C., Estados Unidos de América.

: Desarrollo económico local y difusión del progreso técnico. Cuadernos del ILPES 43. CEPAL, Naciones Unidas, Santiago de Chile. 1997

--------------: La importancia de la producción local y la pequeña empresa para el desarrollo de América Latina. Revista de la CEPAL, Núm. 63, Naciones Unidas, Santiago de Chile, diciembre 1997.

Bitar, S. (1988) Neoliberalismo vs. Neoestructuralismo en América Latina. Revista de la CEPAL, Núm.34, abril.

Borja , J. \& Castells, M. (1997) Local y global. La gestión de las ciudades en la era de la información. UNCHS/Taurus, Madrid, España.

Carreras, A.; Hofman, A.; Tafunell, X \& Yáñez, C. (2003) El desarrollo económico América Latina en épocas de globalización: una agenda de investigación. Serie Estudios Estadísticos y Prospectivos N²4. CEPAL, Santiago de Chile.

CEPAL (1989) Balance preliminar de la economía latinoamericana 1989. Notas sobre la economía y el desarrollo, número 479, julio de 1989. Santiago de Chile.

CEPAL (1990) Transformación productiva con equidad. Santiago de Chile.

De Franco, Silvio (1989) Desarrollo y Orientación Hacia fuera: sumatoria de una nueva panacea. Cuadernos de Economía y Finanzas. Cuaderno No 8, Departamento de Planificación, Banco Centroamericano de Integración Económica, Honduras.

De Souza Silva, José (1999) El Cambio de Época, el Modo Emergente de Generación de Conocimiento y los Papeles Cambiantes de la Investigación y Extensión en la Academia del 
Siglo XXI. Instituto Interamericano de Cooperación para la Agricultura (IICA), Costa Rica.

Erias, A. \& Álvarez-Campana, J. M. (2007) Evaluación Ambiental y Desarrollo Sostenible. Ediciones Pirámide, Madrid, España.

Fajnzylber, F. (1983) La industrialización trunca de América Latina. Editorial Nueva Imagen, México.

FAO (1988) Potencialidades del desarrollo agrícola y rural en América Latina (Informe principal y cinco anexos). Roma, Italia.

Ffrench-Davis, R. (1988) Esbozo de un planteamiento neoestructuralista. Revista de la CEPAL Núm. 34, abril.

Garrido, Santiago (2003) Dirección Estratégica. McGraw-Hill/ Interamericana, Madrid, España.

González, R.L. \& Quintero, R. (1986) La biotecnología y sus impactos: el caso de los nuevos endulcorantes. En Revolución tecnológica y empleo, № I, STPS, México.

Graciarena, J. (1976) Poder y estilos de desarrollo: una perspectiva heterodoxa. Revista de la CEPAL, II semestre, Santiago de Chile. Publicación de las Naciones Unidas.

Hinkelammert, F. \& Mora, H. (2008) Hacia una economía para la vida: Preludio a una Reconstrucción de la Economía. Editorial Tecnológica de Costa Rica, Cartago, Costa Rica.

IICA (2005) Agronegocios para dinamizar la inversión en zonas rurales. Instituto Interamericano de Cooperación para la Agricultura. San José, Costa Rica.

Jiménez, Luis (200I) Desarrollo Sostenible y Economía Ecológica. Editorial Síntesis, Madrid, España.

Junne, G. (1986) Nuevas tecnologías: una amenaza para las exportaciones de los países en desarrollo. En Revolución tecnológica y empleo, № I, STPS, México.

Kozul-Wright, R. (2010) Comercio, empleo y desarrollo: ¿de nuevo encarrilados? Existe una Alternativa: Políticas económicas y estrategias laborales más allá de la corriente dominante. Organización Internacional del Trabajo, Ginebra, Suiza.

Leland Bach, G. (1962) Tratado de Economía, Editorial EFE, Madrid, España.

Lustig, N. (1988) Del estructuralismo al neoestructuralismo: La búsqueda de un paradigma heterodoxo. Colección Estudios CIEPLAN, Núm. 23, marzo.

Mertens, L. (1989) Crisis económica y revolución tecnológica: hacia nuevas estrategias de las organizaciones sindicales. Editorial Nueva Sociedad, Venezuela.

Mintzberg, H.; Lampel, J.; Quinn y Ghoshal, S. (2003) El proceso estratégico. 4ta edición, Prentice Hall, Londres.

Morales, C., Briones A.J. y Ramírez P. (201 I), Innovación y Desarrollo Integral de los Agronegocios en Costa Rica. Editorial Tecnológica, Cartago, Costa Rica.

Monge, R. \& Céspedes, O. (2002) Costa Rica hacia la Economía basada en el Conocimiento. Litografía e Imprenta LIL S.A., San José, Costa Rica

Neef, D. (1998) The Knowledge Economy. Resources for the Knowledge-Based Economy. Butterworth-Heinemann, United State of America.Océano (1993) Diccionario Enciclopédico Océano Uno. San José, Costa Rica.

Ortega, E. ( 1985 ) La opción campesina en las estrategias agrícolas. Pensamiento Iberoamericano, número 8, julio-diciembre, Madrid, España.

Pearce, D. (1999) Diccionario de Economía Moderna. Ediciones Akal, Madrid, España.

Pinto, A. (1976) Notas sobre los estilos de desarrollo en América Latina. Revista de la CEPAL, I Semestre. Santiago de Chile. Publicación de las Naciones Unidas.

Reynolds, L. (1976) Introducción a la Economía. Editorial Biblioteca TECNOS de Ciencias Económicas, Madrid, España.

Robles, H.; Molina, A. \& Fuentes, B. (2005) La economía basada en el conocimiento. Editorial del Centro de Estudios Estratégicos del Instituto Tecnológico y de Estudios Superiores de Monterrey, Guadalajara, Jalisco, México.

Rosales, O. (1988) Balance y renovación en el paradigma estructuralista del desarrollo latinoamericano. Revista de la CEPAL Núm. 34, abril.

Rovira, J. ( 1987) Costa Rica en los años ochenta. Editorial Porvenir, San José Costa Rica.

Rubalcaba, L. (200I) La economía de los servicios a empresas en Europa. Editorial Pirámide, Madrid, España.

Rubalcaba L.; Gago D. \& Maroto A. (2005) Relaciones entre globalización y servicios: ventajas competitivas de los servicios europeos y españoles en el comercio internacional. Competitividad e internacionalización de los servicios en los países europeos. Revista Información Comercial Española $N^{\circ}$ 824, Julio-Agosto 2005. 93-115

Sunkel, O. (|99|) Desarrollo desde dentro: un enfoque neoestructuralista para la América Latina. El Trimestre Económico. Fondo de Cultura Económica, México.

Timmer, C.P.; Falcon, W.P \& Pearson, S.R (1983) Food policy Analysis. Johns Hopkins University Press, Baltimore, United States of America. Page 43.

Todaro, M. (1987) Economía para un mundo en desarrollo. I ${ }^{a}$ Reimpresión de la la edición en español, Editorial Fondo de Cultura Económica, México.

Vargas, L. (1992) Crisis Económica y Ajuste Estructural. Editorial Universidad Estatal a Distancia, San José, Costa Rica.

Villasuso, J.(1992) El Nuevo Rostro de Costa Rica. CEDAL, Heredia, Costa Rica. 